\title{
Comunicação
}

[Communication]

\section{Avaliação clínica da infecção experimental de bezerros com Salmonella Typhimurium}

[Clinical evaluation of experimental Salmonella Typhimurium-infection in calves]

\author{
L.G. Ávila ${ }^{1}$, D.G. Silva ${ }^{2}$, R.A. Sato ${ }^{3}$, J.J. Fagliari ${ }^{4}$ \\ ${ }^{1}$ Aluna de pós-graduação - Faculdade de Medicina Veterinária -Unesp - Araçatuba, SP \\ Rua Clóvis Pestana, 793 \\ 16050-680 - Araçatuba, SP \\ ${ }^{2}$ Aluna de pós-graduação - Faculdade de Ciências Agrárias e Veterinárias-Unesp - Jaboticabal, SP \\ ${ }^{3}$ Médico veterinário autônomo \\ ${ }^{4}$ Faculdade de Ciências Agrárias e Veterinárias-Unesp - Jaboticabal, SP
}

A diarreia neonatal de bezerros acarreta graves prejuízos à pecuária tanto pela mortalidade quanto pelos custos envolvidos com o tratamento e atraso no crescimento dos animais, sendo a salmonelose uma das causas mais importantes, com destaque para Salmonella (S.) enterica subespécie enterica sorotipos Typhimurium e Dublin (Fecteau et al., 2003). A principal porta de entrada para a ocorrência da infecção é a cavidade oral, pela ingestão de água e alimentos contaminados. A bactéria se instala no sistema digestório, principalmente nas porções terminais do íleo e ceco (Kirk et al., 2002; Radostits et al., 2002).

A infecção resulta em ampla variedade de sinais clínicos, em função da idade do animal e do sorotipo envolvido, sendo necessárias doses de $10^{9}$ e $10^{10}$ unidades formadoras de colônia (UFC) de $S$. Typhimurium para provocar a doença em bovinos sadios (Santos et al., 2002). Em bezerros com até oito semanas de idade, a infecção pode causar diarreia aguda, aquosa e fétida, desidratação, desequilíbrio eletrolítico, endotoxemia, bacteremia e morte (Fecteau et al., 2003), sendo a taxa de mortalidade inversamente proporcional à idade (Santos et al., 2002).

Os objetivos do presente estudo foram avaliar o quadro clínico de bezerros submetidos à infecção experimental com $10^{9}$ UFC de $S$. Typhimurium e verificar a viabilidade do modelo experimental na indução da doença em bezerros. $\mathrm{O}$ estudo foi aprovado pelo Conselho de Ética e Bem-Estar Animal da FCAV-UNESP/Jaboticabal (número do protocolo 009986-07).

Foram examinados 12 bezerros machos da raça Holandesa, sadios, com 10 a 15 dias de idade, obtidos de rebanho comercial. Os bezerros foram alojados em abrigos individuais $(1,30 \mathrm{mx} 1,50 \mathrm{mx} 1,35 \mathrm{~m})$ e receberam quatro litros de leite in natura pasteurizado tipo A, duas vezes ao dia, além de ração, feno e água à vontade. Os animais foram distribuídos aleatoriamente em dois grupos experimentais de seis animais e submetidos aos seguintes procedimentos: grupo 1: bezerros infectados experimentalmente, por via oral e com auxílio de seringa estéril, com $10^{9}$ UFC de $S$. Typhimurium suspensas em $10 \mathrm{~mL}$ de caldo Brain Heart Infusion (BHI; CM225Oxoid), antes da primeira mamada do dia; grupo 2 : bezerros que receberam apenas $10 \mathrm{~mL}$ de caldo BHI (grupo controle).

A cepa de $S$. Typhimurium (registro IOC 6333/06) foi isolada originalmente de bezerro infectado naturalmente e cedida pela Fundação Oswaldo Cruz (Manguinhos - RJ). A bactéria foi cultivada de acordo com as recomendações de Wray e Sojka (1981) e quantificada pela técnica de Miles e Misra (1938).

Recebido em 11 de março de 2011 
Os bezerros foram submetidos ao exame físico, de acordo com as recomendações de Feitosa (2008), imediatamente antes da inoculação e a cada 24 horas, durante seis dias após a infecção experimental. O isolamento de $S$. Typhimurium foi realizado a partir de amostras de suabes retais, enriquecidos em caldo selenito cistina (CM699-Oxoid) e tetrationato MullerKauffmann (CM343 - Oxoid) e plaqueados em ágar verde brilhante modificado (CM329-Oxoid) contendo $50 \mu \mathrm{g} / \mathrm{mL}$ de ácido nalidíxico, como preconizado por Rice et al. (1997) e Santos et al. (2002).
Antes da inoculação com $S$. Typhimurium, todos os parâmetros clínicos estavam dentro dos valores considerados normais para a espécie bovina (Feitosa, 2008). Entre 24 e 72 horas após a infecção experimental, todos os animais inoculados com $10^{9}$ UFC de $S$. Typhimurium apresentaram diferentes graus de diarreia (Tab. 1), com presença de muco e/ou estrias de sangue. $\mathrm{O}$ aumento de temperatura foi verificado nos animais infectados entre 48 e 96 horas após a inoculação bacteriana, não tendo sido constatadas alterações clínicas nos animais do grupo-controle.

Tabela 1. Isolamento microbiológico de Salmonella Typhimurium a partir de suabes retais e avaliação clínica dos bezerros infectados experimentalmente com aproximadamente $10^{9}$ UFC de Salmonella Typhimurium

\begin{tabular}{|c|c|c|c|c|c|c|c|c|}
\hline \multirow[t]{2}{*}{$\mathrm{N}^{\circ}$ Bezerro } & \multirow{2}{*}{$\begin{array}{c}\text { Bactéria e } \\
\text { sintomas }\end{array}$} & \multicolumn{7}{|c|}{ Horas após a infecção } \\
\hline & & 0 & 24 & 48 & 72 & 96 & 120 & 144 \\
\hline \multirow[t]{2}{*}{1} & Fezes & - & + & + & + & + & + & + \\
\hline & Sinais clínicos & & $\mathrm{D}$ & $\mathrm{D}$ & $\mathrm{D}$ & DT & $\mathrm{D}$ & \\
\hline \multirow[t]{2}{*}{2} & Fezes & - & + & + & + & + & + & + \\
\hline & Sinais clínicos & & $\mathrm{D}$ & DT & DT & DT & DT & $\mathrm{T}$ \\
\hline \multirow[t]{2}{*}{3} & Fezes & - & + & + & + & + & + & + \\
\hline & Sinais clínicos & & $\mathrm{D}$ & $\mathrm{D}$ & DT & DT & $\mathrm{D}$ & \\
\hline \multirow[t]{2}{*}{4} & Fezes & - & + & + & + & + & + & - \\
\hline & Sinais clínicos & & $\mathrm{D}$ & $\mathrm{D}$ & $\mathrm{D}$ & $\mathrm{D}$ & $\mathrm{D}$ & $\mathrm{D}$ \\
\hline \multirow[t]{2}{*}{5} & Fezes & - & + & + & + & + & + & + \\
\hline & Sinais clínicos & & $\mathrm{D}$ & DT & DT & DT & DT & $\mathrm{D}$ \\
\hline \multirow[t]{2}{*}{6} & Fezes & - & + & + & + & + & + & + \\
\hline & Sinais clínicos & & $\mathrm{D}$ & $\mathrm{D}$ & D & DT & $\mathrm{D}$ & DT \\
\hline
\end{tabular}

+ = presença de Salmonella $;$ - = ausência de Salmonella $; \mathrm{D}=$ diarreia; $\mathrm{T}=$ temperatura acima de $39,5^{\circ} \mathrm{C}$.

O isolamento de $S$. Typhimurium a partir de suabes retais ocorreu 24 horas após a infecção experimental, sendo verificada excreção de forma contínua ou intermitente. Andrews et al. (2008) relataram que a ocorrência do estado de portador é mais comum em casos de infecção por $S$. Dublin, porém, no presente estudo, a eliminação de $S$. Typhimurium nas fezes ocorreu de forma variada e intermitente, sendo que dois animais eliminaram o agente até 14 dias (336 horas) após a inoculação e um animal apresentou resultado positivo no isolamento microbiológico 17 dias (408 horas) após a inoculação.

Apesar da eliminação contínua do agente pelas fezes, os animais encontravam-se clinicamente saudáveis (sem indício de doença), caracterizando o estado de portadores assintomáticos (Bergeron et al., 2010). Devido à continuidade da eliminação do agente pelas fezes, foram realizadas coletas rotineiras por meio de suabes retais, até a constatação de dois resultados negativos no isolamento microbiológico em ambos os caldos de enriquecimento, com intervalo de 15 dias, conforme sugerido por Andrews et al. (2008). Não houve o isolamento de $S$. Typhimurium em nenhuma das amostras de suabes retais dos animais do grupo-controle.

Todos os bezerros inoculados apresentaram sinais clínicos evidentes de infecção, como diarreia e febre, conforme relatado por Wray e Davies (2000), porém sem sinais de desidratação. Foram frequentes os episódios de fezes de consistência pastosa com a presença de estrias de sangue e muco, além da disquesia demonstrada por alguns animais, corroborando os achados de Mohler et al. (2009). 
Não foi observada a ocorrência de óbito, semelhante ao verificado por Andrews et al. (2008), que relataram que a morbidade causada pela $S$. Typhimurium pode variar de 10 a $70 \%$, porém a mortalidade geralmente não é alta. Silva (2007) verificou taxa de mortalidade de $83,3 \%$ em animais inoculados com $S$. Dublin, além da diferença com relação aos quadros de desidratação e diarreia, que foram leves no presente estudo, diferindo dos dados obtidos no experimento realizado por esse autor. No grupo controle, os animais mostraram-se hidratados ao longo do experimento, enquanto no grupo inoculado, os animais apresentaram grau variável de desidratação a partir de 24 horas após a infecção. Não foi observado nenhum animal gravemente desidratado, diferindo do observado por Radostits et al. (2002) e Santos et al. (2002), que afirmaram que a desidratação é um dos achados clínicos mais comuns em animais com salmonelose e está principalmente relacionada à gravidade da diarreia. Este estudo, portanto, mostrou a importância epidemiológica que o sorotipo Typhimurium apresenta em rebanhos comerciais de bovinos.

Os resultados permitem concluir que a administração oral de $10^{9}$ UFC de $S$. Typhimurium em caldo BHI é suficiente para induzir quadro clínico de salmonelose em bezerros com idade entre 10 e 15 dias, cujos principais sinais clínicos constatados foram diarreia e febre.

Palavras-chave: bezerro, salmonelose, diarreia

\begin{abstract}
The clinical conditions of healthy calves infected with $10^{9}$ CFU of Salmonella Typhimurium were evaluated and the viability of the experimental model in disease induction was verified. Twelve male Holstein calves, 10 to 15-days old, were examined. They were allocated into two groups, control and experimentally infected. Animals were submitted to clinical examination after inoculation and at every 24 hours, during six days after infection. Samples of rectal swabs were collected for Salmonella Typhimurium isolation. Results showed that all animals had different degrees of diarrhea, with mucus and bleeding, 24 to 72 hours after experimental infection with Salmonella Typhimurium, accompanied by fever, but no signs of sepsis. The isolation of Salmonella Typhimurium from rectal swabs occurred 24 hours after the infection and there were no deaths during the experiment, which means that this sorovar has an epidemiological importance related to the intermitent or continuous elimination of the bacterium. Results also showed that the oral administration of $10^{9}$ CFU of Salmonella Typhimurium induces clinical signs of salmonellosis in 10 to 15-day-old calves.
\end{abstract}

Keywords: calf, salmonellosis, diarrhea

\section{AGRADECIMENTOS}

Os autores agradecem à FAPESP, pela concessão de bolsa e pelo auxílio financeiro, e à Fundação Oswaldo Cruz, pelo fornecimento da cepa de $S$. Typhimurium.

\section{REFERÊNCIAS BIBLIOGRÁFICAS}

ANDREWS, A.H.; BLOWEY, R.W.; BOYD, H. et al. Medicina bovina: doenças e criação de bovinos. 2.ed. São Paulo: Roca, 2008, 1080p.

BERGERON, N.; CORRIVEAU, J.; LETELLIER, A. et al. Characterization of Salmonella Typhimurium isolates associated with septicemia in swine. Can J. Vet Res., v.74, p.11-17, 2010.
FECTEAU, M.V.; HOUSE, J.K; KOTARSKI, S.F. et al. Efficacy of ceftiofur tratament of experimental salmonellosis in neonatal calves. Am. J. Vet. Res., v.64, p.918-925, 2003.

FEITOSA, F.L.F. Semiologia veterinária: a arte do diagnóstico. 2.ed. Roca: São Paulo, 2008. $754 \mathrm{p}$.

KIRK, J.; ATWILL, E.; HOLMBERG, C. et al. Prevalence of and risk factors for Salmonella in water offered to weaned dairy calves in California. Prev. Vet. Med., v.54, p.169-178, 2002.

MILLES, A.A.; MISRA, S.S. The estimation of the bactericide power of the blood. J. Hyg., v.38, p.732-739, 1938. 
MOHLER, V.L.; IZZO, M.M.; HOUSE, J.K. Salmonella in calves. Vet. Clin. Food Anim., v.25, p.37-54, 2009.

RADOSTITS, O.M.; GAY, G.C.; BLOOD, D.C. et al. Clínica veterinária: um tratado de doenças dos bovinos, ovinos, suínos, caprinos e equinos. 9.ed. Rio de Janeiro: Guanabara Koogan, 2002. 1737p.

SANTOS, R.L.; TSOLIS, R.M.; BAÜMLER, A.J. et al. Hematologic and serum biochemical changes in Salmonella ser Typhimurium-infected calves. Am. J. Vet. Res., v.63, p.1145-1150, 2002.

SILVA, D.G. Estudo clínico, laboratorial e terapêutico da diarreia experimental em bezerros induzida por Salmonella enterica subespécie enterica sorotipo Dublin. 2007. 186f. Tese (Doutorado em Clínica Médica Veterinária) - Faculdade de Ciências Agrárias e Veterinárias, Universidade Estadual Paulista, Jaboticabal, SP.
WRAY, C.; SOJKA, W.J. Salmonella dublin infection of calves: use of small doses to simulate natural infections on the farm. J. Hyg., v.87, p.501-509, 1981.

WRAY, C.; DAVIES, R.H. Salmonella infections in cattle. In: WRAY, C.; WRAY, A. Salmonella in domestic animals. Oxon: CABI Publishing, 2000. p.169-191. 